\title{
Molecular Deposition of a Macrocyclic Cobalt Catalyst on $\mathrm{TiO}_{2}$ Nanoparticles
}

\author{
Chao Liu, ${ }^{\dagger}$ Tong Jin, ${ }^{\dagger}$ Michael E. Louis, ${ }^{\dagger}$ Sebastian A. Pantovich, ${ }^{\dagger}$ Sarah L. Skraba-Joiner, ${ }^{\dagger}$ Tijana \\ Rajh, ${ }^{*, \neq}$ and Gonghu Li ${ }^{*},+$ \\ †Department of Chemistry, University of New Hampshire, Durham, NH 03824, United States \\ *Center for Nanoscale Materials, Argonne National Laboratory, Argonne, Illinois 60439, United States \\ *Corresponding authors. Email: rajh@anl.gov (T.R.); gonghu.li@unh.edu (G.L.)
}

\begin{abstract}
Hybrid photocatalysts consisting of molecular catalysts and solid-state surfaces have demonstrated great potential as robust and efficient systems in solar fuel production. Based on our prior work, we synthesized hybrid photocatalysts by depositing a macrocyclic Co(III) complex on three different $\mathrm{TiO}_{2}$ nanomaterials via a microwave method. The hybrid photocatalysts were tested in $\mathrm{CO}_{2}$ reduction and were thoroughly characterized with spectroscopic (UV-visible, FTIR and EPR) and microscopic (TEM) techniques. The presence of terminal $\mathrm{OH}$ groups on $\mathrm{TiO}_{2}$ surfaces was essential for the molecular deposition of catalytically active $\mathrm{Co}(\mathrm{III})$ sites. On a $\mathrm{TiO}_{2}$ material without such terminal $\mathrm{OH}$ groups, the $\mathrm{Co}(\mathrm{III})$ complex formed amorphous aggregates, which hindered interfacial electron transfer from photoactivated $\mathrm{TiO}_{2}$ to the surface molecular complex. EPR studies further revealed important information regarding the coordination geometry and interaction with $\mathrm{CO}_{2}$ of surface cobalt sites in the hybrid photocatalysts.
\end{abstract}

Keywords: Hybrid photocatalyst, $\mathrm{CO}_{2}$ reduction, titanium dioxide, cobalt cyclam 


\section{Introduction}

Photocatalysis is a promising approach to harvest, convert, and store solar energy. For example, in photocatalytic $\mathrm{CO}_{2}$ reduction, solar energy can be converted into chemical energy and stored in the form of chemical bonds [1-2]. Currently known photocatalysts for $\mathrm{CO}_{2}$ reduction include molecular and supramolecular complexes [3-5] as well as inorganic semiconductors [6-7]. A key challenge for solar fuel production by $\mathrm{CO}_{2}$ reduction is the lack of photocatalytic systems that are both highly efficient and robust under photochemical conditions. In recent years, hybrid photocatalysts combining molecular catalysts with solidstate surfaces have attracted extensive interests from researchers in the field of solar fuels [810]. Such hybrid photocatalysts generally demonstrate enhanced solar conversion efficiency and improved photostability. In this report, we investigate a rare example of hybrid photocatalysts featuring photo-induced electron transfer from titanium dioxide $\left(\mathrm{TiO}_{2}\right)$ to a surface molecular catalyst.

In hybrid systems for solar $\mathrm{CO}_{2}$ reduction, molecular catalysts are covalently attached to solid-state surfaces [9-12], incorporated in frameworks/porous environment [13-16] or confined to surfaces by polymerization [17-18]. Typical solid-state surfaces for molecular $\mathrm{CO}_{2}$ reduction catalysts include periodic mesoporous organosilicas, metal-organic frameworks, and inorganic semiconductors. For example, Takeda and co-workers prepared a hybrid photocatalyst by covalently attaching a tricarbonyl $\operatorname{Re}(\mathrm{I})$ complex on a light-absorbing mesoporous organosilica [16]. Enhanced $\mathrm{CO}_{2}$-to-CO conversion was achieved upon UV light activation of the organosilica and subsequent resonance energy transfer to the Re(I) catalytic centers. In addition, the mesoporous structure protected the molecular Re(I) complex against photochemical decomposition [16]. Similar effects of catalyst heterogenization were observed in photocatalytic $\mathrm{CO}_{2}$ reduction using a $\mathrm{Re}(\mathrm{I})$ catalyst incorporated in a light-absorbing metalorganic framework [19].

Inorganic semiconductors such as $\mathrm{TiO}_{2}$ have been utilized as the solid-state support for several molecular $\mathrm{CO}_{2}$-reduction catalysts [20-26]. Windle and co-workers synthesized a hybrid $\mathrm{Re}(\mathrm{I})$ photocatalyst by grafting a molecular $\mathrm{Re}(\mathrm{I})$ complex onto $\mathrm{TiO}_{2}$ through phosphate groups [24]. The surface immobilization significantly improved photocatalytic activity of the $\mathrm{Re}(\mathrm{I})$ complex in $\mathrm{CO}_{2}$ reduction under visible-light irradiation, which activates the $\operatorname{Re}(\mathrm{I})$ complex but not the $\mathrm{TiO}_{2}$ support. The researchers utilized transient absorption spectroscopy to demonstrate increased lifetime of a reduced $\mathrm{Re}(\mathrm{I})$ intermediate on the $\mathrm{TiO}_{2}$ surface. It was 
suggested that the longer-lived anionic $\mathrm{Re}(\mathrm{I})$ species on $\mathrm{TiO}_{2}$ has a greater probability of reacting with $\mathrm{CO}_{2}$ and undergoing the second reduction required for the production of $\mathrm{CO}$ [24].

Recently, we prepared a hybrid photocatalyst by depositing a molecular Co(III) complex, [Co(cyclam) $\mathrm{Cl}_{2}$ ] Cl where cyclam is 1,4,8,11-tetraazacyclotetradecane, onto $\mathrm{TiO}_{2}$ (Figure 1) [21]. The hybrid photocatalyst was photoactive in $\mathrm{CO}_{2}$ reduction in the presence of sacrificial electron donors. The molecular Co(III) complex was also grafted onto a mesoporous silica for use in photocatalytic $\mathrm{CO}_{2}$ reduction in the presence of a molecular photosensitizer [27]. The best catalytic activity was achieved when the surface Co(III) complex formed a monolayer in the silica mesopores.

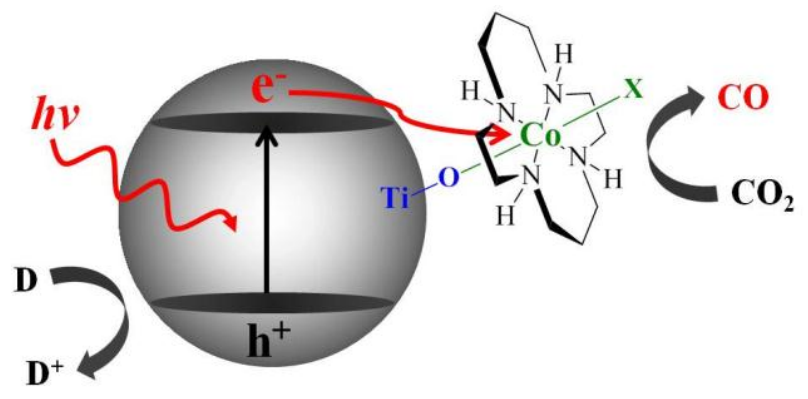

Figure 1. Schematic of the hybrid Co(III) photocatalyst. D is an electron donor. $\mathrm{X}=\mathrm{OH}$ or $\mathrm{Cl}$.

In this work, we build on prior work to demonstrate the importance of molecular deposition in achieving photo-induced electron transfer from $\mathrm{TiO}_{2}$ to the molecular catalyst for $\mathrm{CO}_{2}$ reduction in the presence of an electron donor. We synthesize three hybrid photocatalysts using different $\mathrm{TiO}_{2}$ nanomaterials via a microwave method. We further investigate the hybrid photocatalysts using spectroscopic and microscopic techniques, including UV-visible, Fourier Transform infrared (FTIR) and electron paramagnetic resonance (EPR) spectroscopies, and transmission electron microscopy (TEM). Through these studies, we identify surface characteristics that are key to the molecular deposition of the molecular catalyst, and further investigate coordination geometry of the surface metal sites and their interaction with $\mathrm{CO}_{2}$.

\section{Experimental Section}

Materials. Triethylamine (TEA, $\geq 99 \%$ ), triethanolamine (TEOA, $\geq 99 \%$ ), acetonitrile (99.999\%), hydrochloric acid (37\%), and 1,4,8,11-tetraazacyclotetradecane (cyclam, 98\%) were obtained from Sigma-Aldrich. Methanol (99.9\%) was purchased from Fisher Scientific. 
Cobalt(II) chloride hexahydrate was obtained from J. T. Baker. N,N-dimethylformamide (DMF, 99.8\%) was obtained from Acros Organics. Ethanol (95.0\%) and chloroform (99.8\%) were purchased from Parmo Products Inc. All reagents were used without further purification. P25 $\mathrm{TiO}_{2}$ (specific surface area $57 \mathrm{~m}^{2} / \mathrm{g}$, phase composition $\sim 80 \%$ Anatase and $\sim 20 \%$ Rutile, see Figure S1 in Electronic Supplementary Information) was obtained from Evonik and used as received. Anatase $\mathrm{TiO}_{2}$ nanopowder (99.7\% trace metal basis, specific surface area $56 \mathrm{~m}^{2} / \mathrm{g}$ ) and Rutile $\mathrm{TiO}_{2}$ nanopowder (99.5\% trace metal basis, specific surface area $20 \mathrm{~m}^{2} / \mathrm{g}$ ) were obtained from Sigma-Aldrich and used as received.

Catalyst Synthesis. Hybrid photocatalysts were synthesized by a microwave method (Figure 2). In a typical synthesis, $100 \mathrm{mg} \mathrm{\textrm {TiO } _ { 2 }}$ was mixed with $10 \mathrm{mg}$ [Co(cyclam) $\left.\mathrm{Cl}_{2}\right] \mathrm{Cl}$ and 65 $\mu \mathrm{l}$ triethylamine in $15 \mathrm{ml}$ acetonitrile. The presence of triethylamine was found to be essential for the successful deposition of the $\mathrm{Co}(\mathrm{III})$ catalyst on $\mathrm{TiO}_{2}$ via reacting with surface $\mathrm{Ti}-\mathrm{OH}$ groups. The mixture in a capped reaction vessel was placed in a CEM Discover single-mode microwave reactor and underwent reaction for $120 \mathrm{~min}$ at $80^{\circ} \mathrm{C}$. After the microwave reaction, the resulting brownish precipitate was recovered by centrifugation, and washed twice with chloroform and twice with ethanol. After drying at room temperature, the hybrid photocatalyst was obtained as a light brownish powder. Our previous results [21] clearly indicated that the molecular structure of $\mathrm{Co}^{\mathrm{III}}$ (cyclam) was retained upon deposition on $\mathrm{TiO}_{2}$ surfaces, with some of the $\mathrm{Cl}$ ligands replaced by $\mathrm{OH}$ groups (Figure 2).
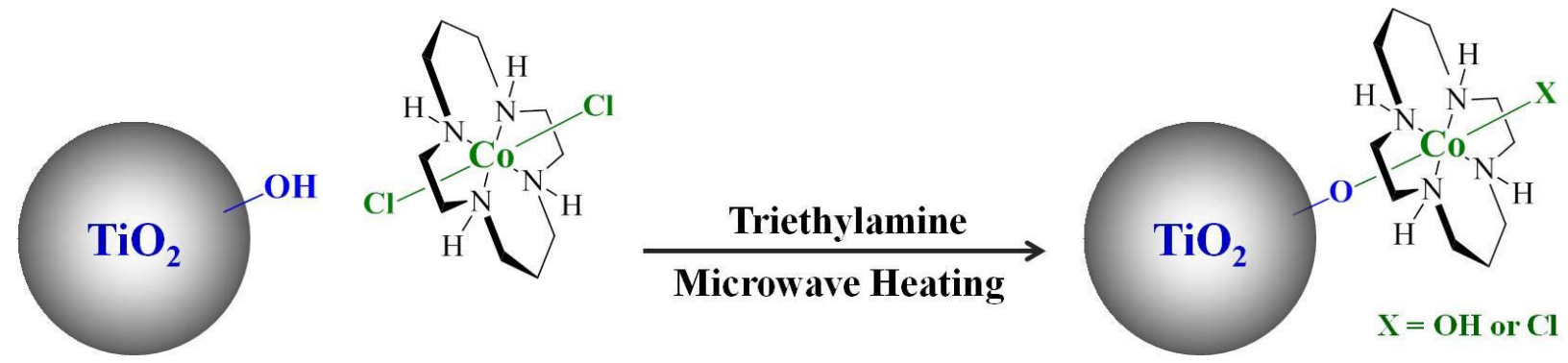

Figure 2. Synthesis of the hybrid photocatalyst in the presence of triethylamine (TEA).

Following this microwave synthesis, three hybrid photocatalysts were prepared in the presence of P25, Anatase and Rutile $\mathrm{TiO}_{2}$ nanomaterials. The three hybrid photocatalysts are denoted as $\mathrm{Co}^{\mathrm{III}}\left(\right.$ cyclam)X/P25, $\mathrm{Co}^{\mathrm{III}}\left(\right.$ cyclam)X/Anatase, and $\mathrm{Co}^{\mathrm{III}}$ (cyclam)X/Rutile. Catalyst 
loadings were determined by elemental analysis to be 59,63 , and $88 \mu \mathrm{mol}$ Co per gram of $\mathrm{Co}^{\mathrm{III}}\left(\right.$ cyclam)X/P25, $\mathrm{Co}^{\mathrm{III}}\left(\right.$ cyclam)X/Anatase, and $\mathrm{Co}^{\mathrm{III}}($ cyclam $) \mathrm{X} /$ Rutile, respectively. The loadings were used to calculate turnover numbers (TONs) in photocatalysis.

Catalyst Characterization. Elemental analysis was conducted by acid digestion of powder samples, followed by quantification using a Varian Vista AX induced coupled plasma atomic emission spectrometer. Transmission electron microscopy images were taken on a Zeiss/LEO 922 Omega system. UV-visible spectra were obtained on a Cary 50 Bio spectrophotometer. A Barrelino diffuse reflectance probe was used to collect UV-visible spectra of powder samples using $\mathrm{BaSO}_{4}$ as a standard. FTIR spectra were collected on a Thermo Nicolet 6700 FTIR spectrometer using a Harrick Praying Mantis diffuse reflectance accessory (for powder samples) or a transmission cell (for gaseous samples). EPR spectra were collected on a Bruker ELEXSYS E580 spectrometer operating in the X-band $(9.4 \mathrm{GHz})$ mode and equipped with an Oxford CF935 helium flow cryostat. Spectra of powder samples were collected under $\mathrm{N}_{2}$ at liquid He temperature. For the studies of $\mathrm{CO}_{2}$ adsorption, the samples were purged with $\mathrm{CO}_{2}$ at room temperature, cooled to liquid He temperature, and illuminated in the EPR cavity using a $300 \mathrm{~W}$ Xe lamp (PerkinElmer) with $400 \mathrm{~nm}$ long-pass and water as IR cutoff filters.

Photocatalytic $\mathrm{CO}_{2}$ Reduction. In photocatalytic $\mathrm{CO}_{2}$ reduction, $1 \mathrm{mg}$ of photocatalyst in the powder form was dispersed in a 4.0-ml acetonitrile solution containing TEOA (acetonitrile : TEOA $=3: 1 \mathrm{v} / \mathrm{v}$ ) in a Pyrex test tube. Prior to photocatalytic testing, the reaction solution was bubbled with $\mathrm{CO}_{2}$ (99.999\%, Airgas) in the dark for $20 \mathrm{~min}$. The reaction solution was then irradiated with a 200-W Hg lamp equipped with a water filter. Light intensity on the reaction solution was fixed at $100 \mathrm{~mW} / \mathrm{cm}^{2}$. The head space above the reaction solution was sampled with a gas-tight syringe at different time intervals for product analysis using an Agilent 7820 GC equipped with a TCD detector. Production of formic acid in reaction solutions was monitored by NMR.

\section{Results and Discussion}

Photocatalysis. Heterogeneous photocatalysts based on $\mathrm{TiO}_{2}$ materials have been extensively investigated in $\mathrm{CO}_{2}$ reduction since the early work by Inoue and co-workers [2832]. Compared to molecular catalysts, semiconductor photocatalysts are relatively stable and 
inexpensive. However, multi-electron processes, including $\mathrm{CO}_{2}$-reduction catalysis, on $\mathrm{TiO}_{2}$ surfaces are extremely inefficient due to recombination of photoexcited charge carriers (electrons and holes) [33-38]. Instead, efficient solar energy conversion has been achieved by surface functionalization of $\mathrm{TiO}_{2}$ nanomaterials with coordination complexes such as $\mathrm{Ru}(\mathrm{II})-$ based dye molecules. In dye-sensitized solar cells [39-43] and photosynthesis cells [44-49], $\mathrm{TiO}_{2}$ serves to accept photoexcited electrons from the surface coordination complexes upon interfacial electron transfer. The success of surface dye sensitization has inspired design of hybrid photocatalysts consisting of $\mathrm{TiO}_{2}$ and surface molecular catalysts [24-25,50-51]. In this study, we utilize $\mathrm{TiO}_{2}$ as a solid-state photosensitizer for $\left[\mathrm{Co}(\right.$ cyclam $\left.) \mathrm{Cl}_{2}\right] \mathrm{Cl}$, which is as a molecular $\mathrm{CO}_{2}$-reduction catalyst based on an earth-abundant metal. This $\mathrm{Co}$ (III) complex demonstrated excellent activity and selectivity in reducing $\mathrm{CO}_{2}$ to $\mathrm{CO}$ in the presence of molecular photosensitizers, including $p$-terphenyl, under UV irradiation [52-53].

The three hybrid photocatalysts, Co ${ }^{\mathrm{III}}\left(\right.$ cyclam)X/P25, Co ${ }^{\mathrm{III}}$ (cyclam)X/Anatase, and $\mathrm{Co}{ }^{\text {III }}\left(\right.$ cyclam)X/Rutile, were evaluated in photocatalytic $\mathrm{CO}_{2}$ reduction in the presence of triethanolamine (TEOA) as a sacrificial electron donor. $\mathrm{Co}^{\mathrm{III}}$ (cyclam)X/P25 and $\mathrm{Co}{ }^{\text {III }}$ (cyclam)X/Anatase exhibited very good activity in photocatalytic $\mathrm{CO}_{2}$ reduction, while negligible CO production was observed using $\mathrm{Co}^{\mathrm{III}}$ (cyclam)X/Rutile (Figure 3). Hydrogen gas $\left(\mathrm{CO} / \mathrm{H}_{2} \sim 1\right)$ as a byproduct was produced using the hybrid photocatalysts.

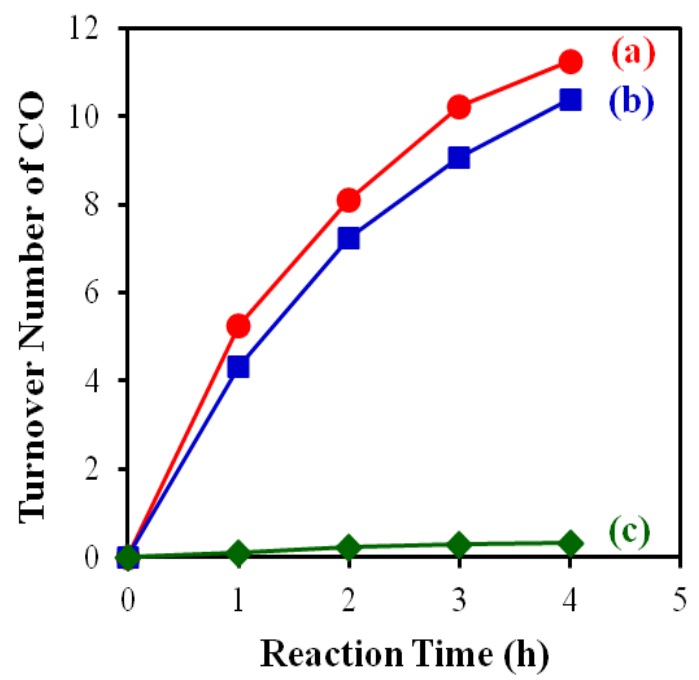

Figure 3. $\mathrm{CO}$ production in photocatalytic $\mathrm{CO}_{2}$ reduction using (a) $\mathrm{Co}^{\mathrm{III}}($ cyclam)X/P25, (b) $\mathrm{Co}^{\mathrm{III}}(\mathrm{cyclam}) \mathrm{X} /$ Anatase, and (c) $\mathrm{Co}^{\mathrm{III}}(\mathrm{cyclam}) \mathrm{X} /$ Rutile. Reaction conditions: UV irradiation, 
TEOA as sacrificial electron donor. Turnover numbers were calculated based on the amount of CO produced per mole of Co in the reaction suspension.

In our study, products in the gas phase were analyzed with a GC. Product detection in the solution phase by NMR indicated no significant production of formate after photocatalysis. In order to rule out the possibility of $\mathrm{CO}$ generation from carbon residues on the synthesized samples, products in the gas phase were also analyzed with FTIR spectroscopy in combination with isotope labeling. Figure 4 displays the FTIR spectrum of the head-space gases above a reaction solution after photocatalytic reduction of ${ }^{13} \mathrm{CO}_{2}$ by $\mathrm{Co}^{\mathrm{III}}$ (cyclam)X/P25 under UV irradiation. In the spectrum, the rotational-vibrational band of gaseous ${ }^{13} \mathrm{CO}$ centered at 2096 $\mathrm{cm}^{-1}$ clearly confirms the production of $\mathrm{CO}$ from $\mathrm{CO}_{2}$ on the hybrid photocatalyst.

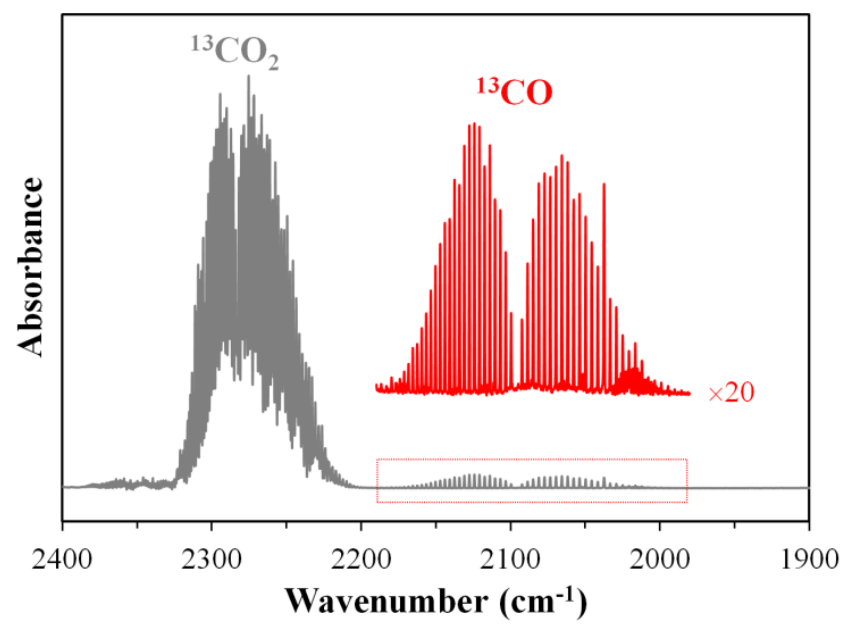

Figure 4. FTIR spectrum of gases in the head space above a reaction solution after photocatalytic reduction of ${ }^{13} \mathrm{CO}_{2}$ by $\mathrm{Co}{ }^{\mathrm{III}}(\mathrm{cyclam}) \mathrm{X} / \mathrm{P} 25$ under UV irradiation for $6 \mathrm{~h}$. See Figure S2 for experimental details.

Under the experimental conditions employed in this study (TEOA, $\mathrm{CO}_{2}$ atmosphere, and UV irradiation), no $\mathrm{CO}$ was produced by any of the following: (i) $\mathrm{P} 25 \mathrm{TiO}_{2}$ nanoparticles, (i) $\left[\mathrm{Co}\right.$ (cyclam) $\left.\mathrm{Cl}_{2}\right] \mathrm{Cl}$ and $\mathrm{P} 25$, or (iii) $\mathrm{Co}^{\mathrm{III}}\left(\right.$ cyclam) $\mathrm{X} / \mathrm{SiO}_{2}$ prepared by depositing the $\mathrm{Co}$ (III) complex on a fumed silica following the microwave synthesis. In addition, no $\mathrm{CO}$ formation was observed using Co ${ }^{\mathrm{III}}$ (cyclam)X/P25 under visible-light irradiation $(\lambda>420 \mathrm{~nm})$ which cannot activate $\mathrm{P} 25 \mathrm{TiO}_{2}$. Therefore, in this hybrid $\mathrm{Co}{ }^{\mathrm{III}}\left(\right.$ cyclam) $\mathrm{X} / \mathrm{TiO}_{2}$ system the surface $\mathrm{Co}(\mathrm{III})$ 
complex is the catalyst for $\mathrm{CO}_{2}$ reduction while $\mathrm{TiO}_{2}$ nanoparticles function as the lightharvesting support (Figure 1).

FTIR Spectroscopy. Further surface chemistry studies also indicate that $\mathrm{CO}_{2}$ reduction occurs on the surface Co(III) sites. In the surface chemistry studies, a hybrid photocatalyst in the powder form was placed in a diffuse reflectance accessory and exposed to an atmosphere of $\mathrm{CO}_{2}$. Photocatalysis at the gas-surface interface was carried out in the absence of any solvent or TEOA. The photocatalyst surface was monitored with in situ infrared detection [54-55]. At various stages during photocatalysis, difference FTIR spectra were obtained by subtracting spectra acquired prior to photocatalysis from corresponding spectra collected after UV irradiation. Therefore, the difference spectra provide information regarding changes on the photocatalyst surface upon light irradiation. The formation of $\mathrm{CO}$ was observed on surface Co(III) sites in Co ${ }^{\mathrm{III}}$ (cyclam)X/P25 and $\mathrm{Co}^{\mathrm{III}}$ (cyclam)X/Anatase, as indicated by the infrared bands at $2193 \mathrm{~cm}^{-1}$ in the spectra shown in Figure 5 (a and b) [56]. The formation of surface carbonate species $\left(1720 \mathrm{~cm}^{-1}\right)$ was also observed on these two samples. Negligible changes were observed on $\mathrm{Co}^{\mathrm{III}}(\mathrm{cyclam}) \mathrm{X} /$ Rutile during photocatalysis (Figure $5 \mathrm{c}$ ). The comparison shown in Figure 5 is in excellent agreement with photocatalysis in the solution phase (Figure 3). Under the same experimental conditions, surface CO species was not observed on bare P25 $\mathrm{TiO}_{2}$,[21] further confirming the key role of surface $\mathrm{Co}(\mathrm{III})$ sites in mediating $\mathrm{CO}_{2}$-reduction catalysis.

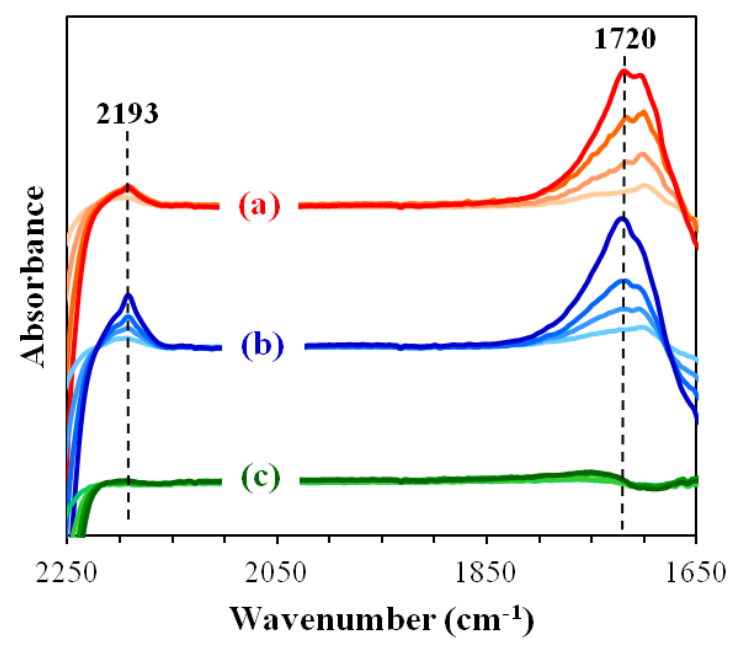


Figure 5. Difference FTIR spectra obtained after photocatalysis at the gas-surface interface using (a) $\mathrm{Co}^{\mathrm{III}}\left(\right.$ cyclam)X/P25, (b) $\mathrm{Co}^{\mathrm{III}}$ (cyclam)X/Anatase, and (c) $\mathrm{Co}^{\mathrm{III}}$ (cyclam)X/Rutile. For each sample, spectra were collected after UV irradiation for 5, 15, 30, 60 min (bottom to top).

These photocatalysis results clearly indicate photoexcited electron transfer from the $\mathrm{TiO}_{2}$ conduction band to the surface $\mathrm{Co}(\mathrm{III})$ catalyst for $\mathrm{CO}_{2}$ reduction in the presence of a sacrificial electron donor. In our previous studies, reduction potentials of the $\mathrm{Co}{ }^{\mathrm{III}} / \mathrm{Co}^{\mathrm{II}}$ and $\mathrm{Co}^{\mathrm{II}} / \mathrm{Co}^{\mathrm{I}}$ redox couples for $\mathrm{Co}^{\mathrm{III}}$ (cyclam)X were measured to be $-0.21 \mathrm{~V}$ and $-0.93 \mathrm{~V}$ vs $\mathrm{NHE}$, respectively [21]. Therefore, photoexcited electrons in the $\mathrm{TiO}_{2}$ conduction band (potential $-0.6 \mathrm{~V}$ vs NHE at $\mathrm{pH}=7$ ) [57] are not energetic enough to reduce Co(II) to Co(I) needed to catalyze $\mathrm{CO}_{2}$-to-CO conversion (-0.53 V vs. NHE). The exact driving force for the photoexcited electron transfer is unclear. However, we note that the reduction potential of $\mathrm{Co}^{\mathrm{II}} / \mathrm{Co}^{\mathrm{I}}$ is largely dependent of coordination ligands. For example, the reduction potential of $\mathrm{Co}^{\mathrm{II}} / \mathrm{Co}^{\mathrm{I}}$ for [Co(cyclam) $\mathrm{Cl}_{2}$ ]Cl was $-1.39 \mathrm{~V}$ vs NHE, in comparison to $-0.93 \mathrm{~V}$ vs NHE for $\mathrm{Co}^{\mathrm{III}}$ (cyclam)X [21]. The Ti-O-Co linkage in our hybrid photocatalysts (Figure 1) and the presence of excess TEOA in reaction solutions could further alter the redox properties of the $\mathrm{Co}^{\mathrm{III}}$ (cyclam) unit on $\mathrm{TiO}_{2}$ surfaces under photochemical conditions. The importance of such surface Ti-O-Co linkage is further described in the following spectroscopic and microscopic studies.

UV-Visible Spectroscopy. As shown in Figure 3, the hybrid photocatalyst prepared on the Rutile nanopowder demonstrated much lower activity than $\mathrm{Co}^{\mathrm{III}}$ (cyclam)X/P25 and $\mathrm{Co}^{\mathrm{III}}$ (cyclam)X/Anatase. In many photocatalytic applications using bare $\mathrm{TiO}_{2}$ materials, the rutile phase is generally considered less active than the anatase phase due to more significant charge recombination in rutile [29]. However, the particular Rutile nanopowder employed in our study is more active than the Anatase nanopowder in photocatalytic degradation of methylene blue (Figure S3), despite its lower surface area. Therefore, the difference in charge carrier dynamics is not responsible for the observed difference in photocatalytic activity shown in Figure 3.

In the UV-visible spectra of $\mathrm{Co}^{\mathrm{III}}$ (cyclam)X/P25 and $\mathrm{Co}^{\mathrm{III}}$ (cyclam)X/Anatase, two broad absorptions are seen at $\sim 450 \mathrm{~nm}$ and $600 \mathrm{~nm}$, indicating the presence of macrocyclic Co(III) complex (Figure 6, a and b) [21]. However, these features are not distinguishable in the spectrum of $\mathrm{Co}^{\mathrm{III}}\left(\right.$ cyclam)X/Rutile (Figure 6c). Therefore, the state of $\mathrm{Co}^{\mathrm{III}}($ cyclam)X on the 
Rutile material is different from that on P25 and Anatase. Such difference might account for the observed photocatalytic activity displayed in Figure 3. Furthermore, there is no significant amount of cobalt oxides, which would exhibit distinguishable peaks at 530,595, and $655 \mathrm{~nm}$ [27], in the synthesized photocatalysts.

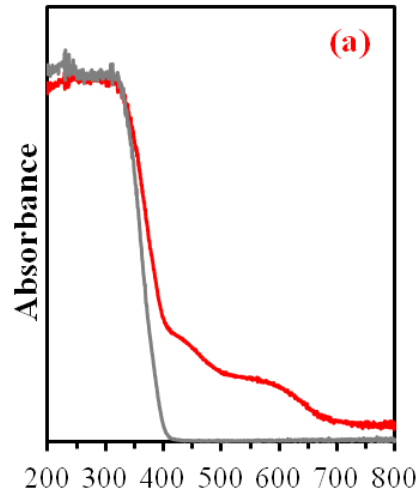

Wavelength $(\mathbf{n m})$

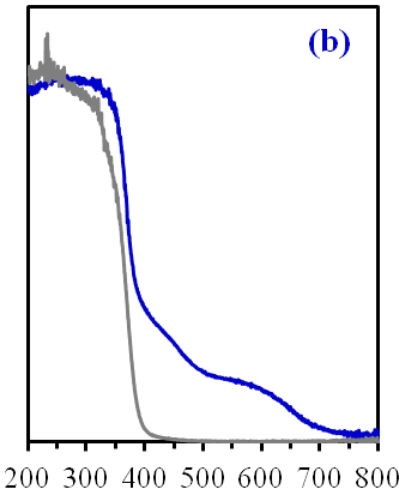

Wavelength $(\mathbf{n m})$

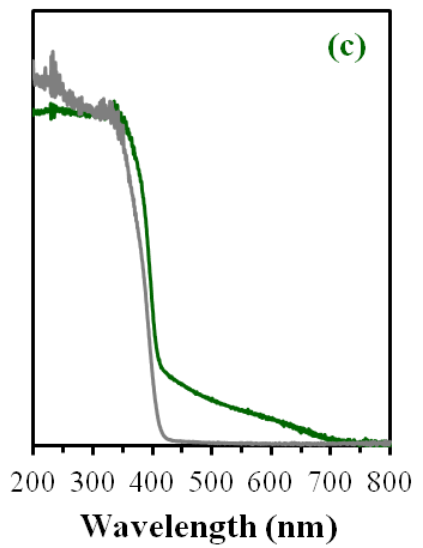

Wavelength (nm)

Figure 6. UV-visible spectra of (a) $\mathrm{Co}^{\mathrm{III}}\left(\right.$ cyclam)X/P25, (b) $\mathrm{Co}^{\mathrm{III}}$ (cyclam)X/Anatase, and (c) Co ${ }^{\text {III }}$ (cyclam)X/Rutile. The spectra of corresponding bare $\mathrm{TiO}_{2}$ materials are also plotted (gray).

Transmission Electron Microscopy. In combination with UV-visible spectroscopic studies, microscopic investigation of the hybrid photocatalysts indicates that $\mathrm{Co}^{\mathrm{III}}(\mathrm{cyclam}) \mathrm{X}$ is molecularly deposited as a thin layer on P25 and Anatase surfaces. Only $\mathrm{TiO}_{2}$ nanoparticles are observed in the TEM images of $\mathrm{Co}^{\mathrm{III}}$ (cyclam)X/P25 and $\mathrm{Co}^{\mathrm{III}}$ (cyclam)X/Anatase (Figure 7, a and b). Close inspection of the TEM images indicates that no separate phase is present in either of these two samples. In comparison, amorphous, nano-sized particles are seen in the TEM image of $\mathrm{Co}^{\mathrm{III}}($ cyclam)X/Rutile (Figure 7c). These particles are either attached to the Rutile nanoparticles (Figure 7d) or form large aggregates (Figure 8). Further comparison with the TEM image of bare Rutile confirms that these amorphous particles are $\mathrm{Co}^{\mathrm{III}}$ (cyclam) $\mathrm{X}$ in the solid state that formed during the synthesis of $\mathrm{Co}^{\text {III }}($ cyclam)X/Rutile. 

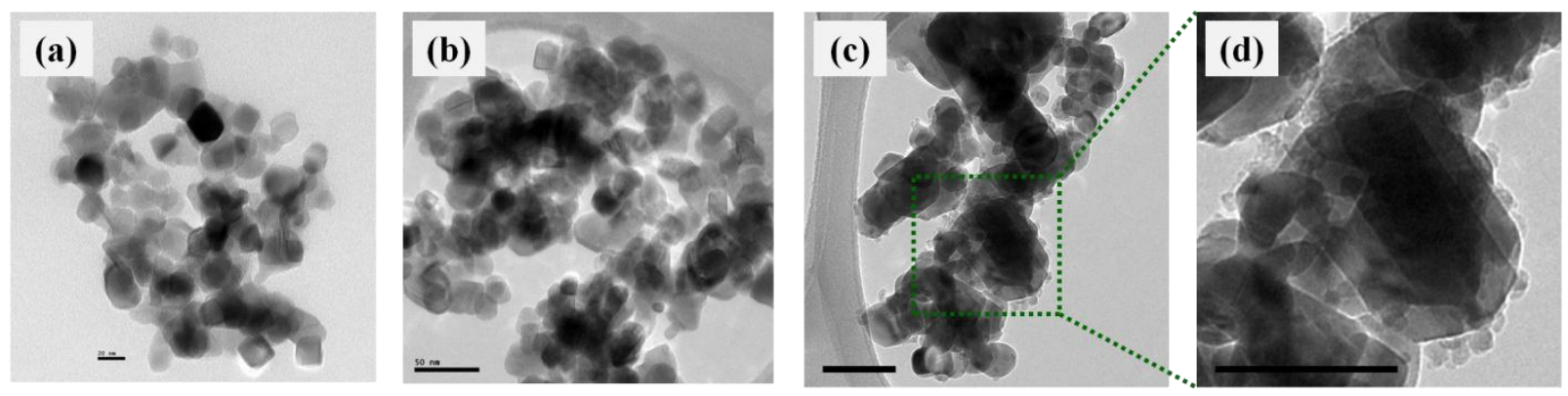

Figure 7. TEM images of (a) $\mathrm{Co}^{\mathrm{III}}\left(\right.$ cyclam)X/P25, (b) $\mathrm{Co}^{\mathrm{III}}($ cyclam)X/Anatase, and (c, d) $\mathrm{Co}^{\mathrm{III}}($ cyclam)X/Rutile. Scale bars are (a) $20 \mathrm{~nm}$, (b) $50 \mathrm{~nm}$, and (c, d) $100 \mathrm{~nm}$.
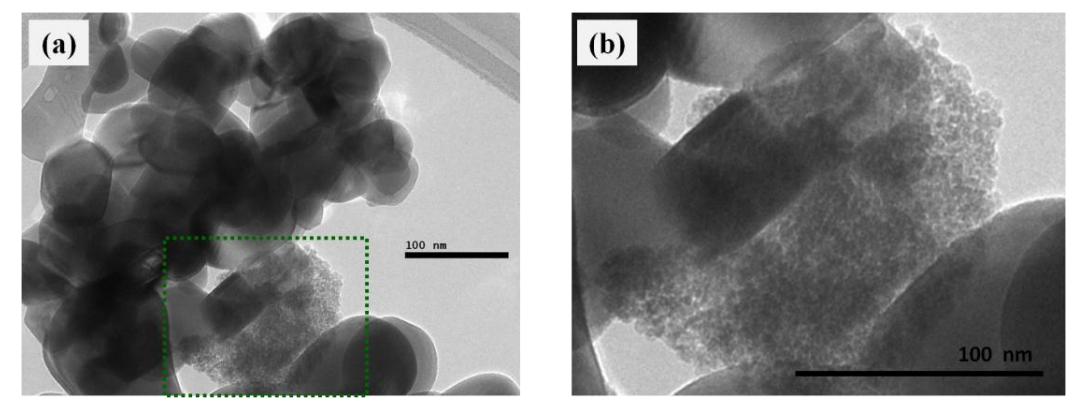

Figure 8. TEM images of $\mathrm{Co}^{\mathrm{III}}($ cyclam)X/Rutile. Image (b) is an enlarged view of the highlighted area in image (a). Scale bars are $100 \mathrm{~nm}$.

Previously we have found that surface $\mathrm{Ti}-\mathrm{OH}$ groups are important for successful deposition of active $\mathrm{Co}(\mathrm{III})$ catalysts on $\mathrm{TiO}_{2}$ nanoparticles via a reflux method [21]. Similar results were obtained for the three hybrid photocatalysts prepared by the microwave method in this study. Infrared studies of the hybrid photocatalysts show that the Rutile surface lacks terminal Ti-OH groups associated with a band at $3632 \mathrm{~cm}^{-1}$ (Figure S4) for effective deposition of $\mathrm{Co}^{\mathrm{III}}\left(\right.$ cyclam)X. According to the UV-visible and TEM results (Figures 6-8), $\mathrm{Co}^{\mathrm{III}}$ (cyclam)X is molecularly deposited as a thin layer on P25 and Anatase surfaces but forms aggregates on Rutile. In the study by Petsi and co-workers [58], both bridging and terminal $\mathrm{OH}$ groups were found to be important for the deposition of $\left[\mathrm{Co}\left(\mathrm{H}_{2} \mathrm{O}\right)_{6}\right]^{2+}$ on $\mathrm{TiO}_{2}$ nanoparticles. In our study, the presence of terminal $\mathrm{OH}$ group associated with the infrared absorption at $3632 \mathrm{~cm}^{-1}$ is essential for the molecular deposition of catalytically active $\mathrm{Co}^{\mathrm{III}}$ (cyclam)X on P25 and Anatase surfaces via Ti-0-Co linkages (Figure 1).

Based on the specific surface areas of the $\mathrm{TiO}_{2}$ nanomaterials and elemental analysis results, surface catalyst densities are estimated to be 6-7 Co per $\mathrm{nm}^{2}$ surface area in 
$\mathrm{Co}^{\mathrm{III}}\left(\right.$ cyclam)X/P25 and $\mathrm{Co}^{\mathrm{III}}\left(\right.$ cyclam)X/Anatase, and $\sim 26$ Co per $\mathrm{nm}^{2}$ surface area in $\mathrm{Co}^{\text {III }}$ (cyclam)X/Rutile. These numbers further support our conclusion that $\mathrm{Co}^{\mathrm{III}}(\mathrm{cyclam}) \mathrm{X}$ is molecularly deposited on P25 and Anatase surfaces. The absence of terminal $\mathrm{OH}$ groups for effective deposition of $\mathrm{Co}^{\mathrm{III}}$ (cyclam)X on the Rutile material resulted in the formation of $\mathrm{Co}^{\mathrm{III}}($ cyclam)X in the aggregated form as observed in Figures 7 and 8. The lack of sufficient TiO-Co linkages in $\mathrm{Co}^{\mathrm{III}}$ (cyclam)X/Rutile can be used to explain inefficient photoexcited electron transfer from Rutile to surface $\mathrm{Co}^{\mathrm{III}}$ (cyclam)X, which led to its poor activity in photocatalytic $\mathrm{CO}_{2}$ reduction (Figure 3).

An infrared band at $3670 \mathrm{~cm}^{-1}$, associated with bridging Ti-OH groups, is also present in the spectra of the three $\mathrm{TiO}_{2}$ samples (Figure S4). This infrared band disappeared in the spectra of the three hybrid photocatalysts, indicating that deposition of $\mathrm{Co}^{\mathrm{III}}$ (cyclam)X also occurred through reacting with the bridging Ti-OH groups. However, comparison shown in Figures 4-7 suggests that catalyst deposition through these bridging Ti-OH groups didn't allow photoexcited electron transfer from $\mathrm{TiO}_{2}$ to surface $\mathrm{Co}^{\mathrm{III}}$ (cyclam)X.

EPR Spectroscopy. Characterization with EPR spectroscopy further supports the fact that surface cobalt sites exist in different states on Rutile than on P25 and Anatase surfaces. Although the Co(III) compound itself is EPR silent, some paramagnetic Co(II) species and radicals are present in the synthesized hybrid photocatalysts, as indicated by the following EPR results. This is similar to the study by Kohno and co-workers [59], in which paramagnetic Co(II) species were found to be trapped in single crystals of a Co(III) compound. The presence of paramagnetic Co(II) species is likely a consequence of the use of triethylamine in the synthesis of our hybrid photocatalysts.

The EPR spectra of $\mathrm{Co}^{\mathrm{III}}$ (cyclam)X/P25 and $\mathrm{Co}^{\mathrm{III}}$ (cyclam)X/Anatase are almost identical, except for a dark signal in the latter due to trace metal impurity in the Anatase nanopowder (Figure S5). Therefore, the spectra of $\mathrm{Co}^{\mathrm{III}}\left(\right.$ cyclam)X/P25 and $\mathrm{Co}^{\mathrm{III}}($ cyclam)X/Rutile are chosen for comparison in this section. In the spectrum of $\mathrm{Co}^{\mathrm{III}}$ (cyclam)X/P25 under $\mathrm{N}_{2}$ (Figure 9a, gray trace), resonances corresponding to mononuclear high-spin Co(II) $(S=3 / 2)$ centers are observed at $g_{x}=5.89, g_{y}=3.40$, and $g_{z}=2.22$ (not labeled). The same spectrum also contains resonances near $g=2$ (not labeled) that are associated with trapped electrons and holes [3334] in P25 upon exposure to ambient light (Figure S6). In the spectrum of CoII (cyclam)X/Rutile (Figure 9b, gray trace), however, a very different EPR spectrum is observed in the high-spin 
region consisting of a broad Co(II) peak with $g=5.35$ that suggests averaging of $g_{x}$ and $g_{y}$ components indicative of $\mathrm{Co}$ (II) in a broad range of coordination geometries. The overall spectrum shows evidence of weakly distinguishable hyperfine structure from the ${ }^{59} \mathrm{Co}$ nuclear spin momentum in a lower field component with a hyperfine coupling of $~ 350$ G. Since Co has a nuclear spin of $7 / 2100 \%$ abundance, Co hyperfine has eight lines. These spectra are consistent with those expected for $S=3 / 2$ molecules subject to zero-field splitting where only the $( \pm 1 / 2)$ Kramers' doublet is resonant. The hyperfine contribution is much more evident in the region of $g=2$ where strong eight-line signals are observed. However the hyperfine splitting in this region of the spectrum is much smaller ( $86 \mathrm{G}$ ). The hyperfine splitting of Co(II) is usually in the range between $150 \mathrm{G}$ and $300 \mathrm{G}$ in the low-field region. The small hyperfine coupling and different saturation properties of the signal around $g \sim 2$ from the one of high spin Co are consistent with the existence of surface radicals whose EPR transitions split into eight lines due to the presence of ${ }^{59} \mathrm{Co}$ in close proximity. Since the $g$ value is $\sim 2$, these transitions are mostly likely associated with oxygen-centered radicals. Close inspection of the spectra shows existence of three sets of eight-line splitting, suggesting the existence of three sets of oxygencentered radicals with $g=2.141,2.028$, and 2.019 (Figure S7).

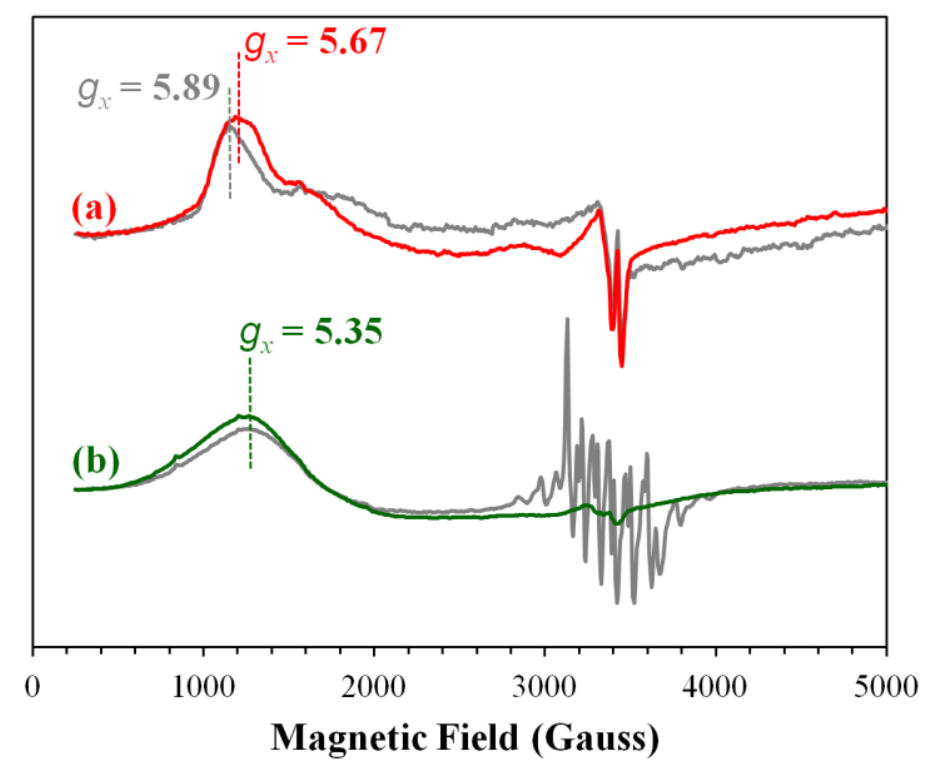

Figure 9. X-band EPR spectra of (a) $\mathrm{Co}^{\mathrm{III}}$ (cyclam)X/P25 and (b) $\mathrm{Co}^{\mathrm{III}}$ (cyclam)X/Rutile under $\mathrm{CO}_{2}$. Corresponding spectra under $\mathrm{N}_{2}$ are also included (gray traces). The spectra were collected at liquid He temperature. 
Therefore, the Co(II) sites in $\mathrm{Co}^{\mathrm{III}}$ (cyclam)X/Rutile are in a broad range of coordination geometries different than those in $\mathrm{Co}^{\mathrm{III}}($ cyclam)X/P25. Likely, oxygen molecules are coordinated to Co centers in the large aggregates of $\mathrm{Co}^{\mathrm{III}}$ (cyclam)X deposited on Rutile (Figure 7, c and d; and Figure 8), but not in $\mathrm{Co}^{\mathrm{III}}$ (cyclam)X/P25 or Co ${ }^{\mathrm{III}}$ (cyclam)X/Anatase where the Co sites are molecularly deposited on $\mathrm{TiO}_{2}$ surfaces through Ti-O-Co linkages (Figure 1).

The adsorption of $\mathrm{CO}_{2}$ on the hybrid photocatalysts was carried out by exposing the samples to $\mathrm{CO}_{2}$ at room temperature and then freezing the samples at liquid He temperature prior to collecting EPR spectra. Binding of $\mathrm{CO}_{2}$ to the $\mathrm{Co}$ (II) sites in $\mathrm{Co}^{\mathrm{III}}$ (cyclam)X/P25 shifted the high-spin signal from $g_{x}=5.89$ to $g_{x}=5.67$ (Figure 9a). The comparison between the Co(II) resonances observed for $\mathrm{Co}^{\mathrm{III}}$ (cyclam)X/P25 is very similar to that between Co(II) sites in zeolite frameworks without and with calcinations at elevated temperatures [60-61]. In particular, a Co(II) signal around $g_{x}=5.80$ was observed in the EPR spectrum of a cobaltcontaining microporous aluminophosphate. The Co(II) signal shifted to $g_{x}=5.44$ upon calcination of the microporous material, which induced changes in the coordination geometry of the Co(II) accompanied with shortening of Co-O bond [60]. Therefore, our observation indicates that $\mathrm{CO}_{2}$ upon adsorption on $\mathrm{Co}^{\mathrm{III}}$ (cyclam)X/P25 took electron density away from the Co(II) centers, either directly or indirectly by interacting with neighboring Ti(IV) sites shifting the $g$ value towards higher fields. In $\mathrm{Co}^{\mathrm{III}}$ (cyclam)X/Rutile (Figure 9b), binding of $\mathrm{CO}_{2}$ did not change the high-spin Co(II) signal at $g_{x}=5.35$. Instead, the hyperfine splitting of the oxygen radicals vanished and an anisotropic signal appeared near $g=2$ (not labeled). This observation implies that the electron density on the oxygen radicals adjacent to Co(II) was preferentially transferred to $\mathrm{CO}_{2}$ and adsorption of $\mathrm{CO}_{2}$, in fact, removed electron exchange of $\mathrm{Co}(\mathrm{II})$ with oxygen atoms on the Rutile surface.

The results shown in Figure 8 provide important insights regarding the coordination geometry of $\mathrm{Co}(\mathrm{II})$ centers as well as interaction of $\mathrm{CO}_{2}$ with the surface $\mathrm{Co}$ (II) sites. Most likely, the coordination geometry of surface $\mathrm{Co}$ (III) sites in $\mathrm{Co}^{\mathrm{III}}$ (cyclam)X/Rutile is also different than that in $\mathrm{Co}^{\mathrm{III}}$ (cyclam)X/P25 and $\mathrm{Co}^{\mathrm{III}}$ (cyclam)X/Anatase. Further studies are underway to probe $\mathrm{CO}_{2}$ reduction under photochemical conditions with EPR spectroscopy.

\section{Conclusions}

In summary, we have synthesized hybrid photocatalysts by depositing a macrocyclic $\mathrm{Co}$ (III) complex on three different $\mathrm{TiO}_{2}$ nanomaterials via a microwave method. In the presence 
of triethanolamine as an electron donor, $\mathrm{TiO}_{2}$ nanoparticles were activated upon UV irradiation and transferred electrons to the surface $\mathrm{Co}(\mathrm{III})$ catalyst for $\mathrm{CO}_{2}$ reduction. Experimental results based on UV-visible and infrared spectroscopy and transmission electron microscopy indicate that catalytically active $\mathrm{Co}(\mathrm{III})$ sites were molecularly deposited on $\mathrm{TiO}_{2}$ surfaces through reacting with terminal $\mathrm{OH}$ groups. In the absence of such terminal $\mathrm{OH}$ groups, the $\mathrm{Co}(\mathrm{III})$ complex formed amorphous aggregates on $\mathrm{TiO}_{2}$ nanoparticles. Molecularly deposited $\mathrm{Co}$ (III) sites demonstrated significantly higher activity than aggregates of the Co(III) complex in photocatalytic $\mathrm{CO}_{2}$ reduction because of efficient interfacial electron transfer from

photoactivated $\mathrm{TiO}_{2}$ to the former. Further studies with electron paramagnetic resonance spectroscopy indicated the presence of paramagnetic Co(II) species in the synthesized hybrid photocatalysts. The spectroscopic investigation also revealed important differences in the coordination geometry and interactions with $\mathrm{CO}_{2}$ of the $\mathrm{Co}$ (II) sites between the molecularly deposited and aggregated cobalt sites. Our results highlight the importance of surface characteristics in the fabrication of hybrid photocatalysts consisting of molecular complexes on metal oxide surfaces.

\section{Acknowledgments}

This research conducted at the University of New Hampshire was supported by the U.S. National Science Foundation through grants CBET-1510810 to G.L. The EPR work was performed at Argonne National Laboratory, the Center for Nanoscale Materials, a U.S. Department of Energy, Office of Science, Office of Basic Energy Sciences User Facility under Contract No. DE-AC02-06CH11357. The generous donation of $\mathrm{P} 25 \mathrm{TiO}_{2}$ by Evonik is greatly appreciated. We are grateful to Drs. Alexander Cowan, Richard Johnson, and Scott Greenwood for helpful discussions and assistance in various aspects of experiments.

\section{References}

[1] A. M. Appel, J. E. Bercaw, A. B. Bocarsly et al., Chem. Rev. 113 (2013) 6621-6658.

[2] M. Mikkelsen, M. Jorgensen, F. C. Krebs, Energy Environ. Sci. 3 (2010) 43-81.

[3] Y. Yamazaki, H. Takeda, O. Ishitani, J. Photochem. Photobiol. C 25 (2015) 106-137.

[4] A. J. Morris, G. J. Meyer, E. Fujita, Acc. Chem. Res. 42 (2009) 1983-1994.

[5] E. E. Benson, C. P. Kubiak, A. J. Sathrum, J. M. Smieja, Chem. Soc. Rev. 38 (2009) 89-99.

[6] J. L. White, M. F. Baruch, J. E. Pander Iii et al., Chem. Rev. 115 (2015) 12888-12935. 
[7] S. N. Habisreutinger, L. Schmidt-Mende, J. K. Stolarczyk, Angew. Chem., Int. Ed. 52 (2013) 7372-7408.

[8] P. D. Tran, L. H. Wong, J. Barber, J. S. C. Loo, Energy Environ. Sci. 5 (2012) 5902-5918.

[9] C. D. Windle, E. Reisner, Chimia 69 (2015) 435-441.

[10] M. E. Louis, T. G. Fenton, J. Rondeau, T. Jin, G. Li, Comments Inorg. Chem. 36 (2016) 38-60.

[11] C. Liu, K. D. Dubois, M. E. Louis, A. S. Vorushilov, G. Li, ACS Catal. 3 (2013) 655-662.

[12] T. G. Fenton, M. E. Louis, G. Li, J. Mol. Catal. A 411 (2016) 272-278.

[13] Y. Ueda, H. Takeda, T. Yui, K. Koike, Y. Goto, S. Inagaki, O. Ishitani, ChemSusChem 8 (2015) 439-442.

[14] M. L. Macnaughtan, H. S. Soo, H. Frei, J. Phys. Chem. C 118 (2014) 7874-7885.

[15] J.-L. Wang, C. Wang, W. Lin, ACS Catal. 2 (2012) 2630-2640.

[16] H. Takeda, M. Ohashi, T. Tani, O. Ishitani, S. Inagaki, Inorg. Chem. 49 (2010) 4554-4559.

[17] K. Maeda, K. Sekizawa, O. Ishitani, Chem. Commun. 49 (2013) 10127-10129.

[18] T. Arai, S. Tajima, S. Sato, K. Uemura, T. Morikawa, T. Kajino, Chem. Commun. 47 (2011) 12664-12666.

[19] C. Wang, Z. Xie, K. E. deKrafft, W. Lin, J. Am. Chem. Soc. 133 (2011) 13445-13454.

[20] C. L. Anfuso, R. C. Snoeberger, III, A. M. Ricks, W. Liu, D. Xiao, V. S. Batista, T. Lian, J. Am. Chem. Soc. 133 (2011) 6922-6925.

[21] T. Jin, C. Liu, G. Li, Chem. Commun. 50 (2014) 6221-6224.

[22] E.-G. Ha, J.-A. Chang, S.-M. Byun, C. Pac, D.-M. Jang, J. Park, S. O. Kang, Chem. Commun. 50 (2014) 4462-4464.

[23] G. Neri, J. J. Walsh, C. Wilson et al., Phys. Chem. Chem. Phys. 17 (2015) 1562-1566.

[24] C. D. Windle, E. Pastor, A. Reynal, A. C. Whitwood, Y. Vaynzof, J. R. Durrant, R. N. Perutz, E. Reisner, Chem. - Eur. J. 21 (2015) 3746-3754.

[25] D.-I. Won, J.-S. Lee, J.-M. Ji, W.-J. Jung, H.-J. Son, C. Pac, S. O. Kang, J. Am. Chem. Soc. 137 (2015) 13679-13690.

[26] R. Kuriki, K. Sekizawa, O. Ishitani, K. Maeda, Angew. Chem., Int. Ed. 54 (2015) 2406-2409.

[27] T. Jin, C. Liu, G. Li, J. Coord. Chem. (2016) in press. DOI:10.1080/00958972.2016.1190452.

[28] T. Inoue, A. Fujishima, S. Konishi, K. Honda, Nature 277 (1979) 637-638.

[29] G. Li, K. A. Gray, Chem. Phys. 339 (2007) 173-187.

[30] N. M. Dimitrijevic, B. K. Vijayan, O. G. Poluektov, T. Rajh, K. A. Gray, H.-Y. He, P. Zapol, J. Am. Chem. Soc. 133 (2011) 3964-3971. 
[31] D. Finkelstein-Shapiro, S. H. Petrosko, N. M. Dimitrijevic, D. Gosztola, K. A. Gray, T. Rajh, P. Tarakeshwar, V. Mujica, J. Phys. Chem. Lett. 4 (2013) 475-479.

[32] L. Liu, Y. Li, Aerosol Air Qual. Res. 14 (2014) 453-469.

[33] D. C. Hurum, A. G. Agrios, K. A. Gray, T. Rajh, M. C. Thurnauer, J. Phys. Chem. B 107 (2003) 4545-4549.

[34] D. C. Hurum, K. A. Gray, T. Rajh, M. C. Thurnauer, J. Phys. Chem. B 109 (2005) 977-980.

[35] G. Li, N. Dimitrijevic, L. Chen, J. Nichols, T. Rajh, K. A. Gray, J. Am. Chem. Soc. 130 (2008) 5402-5403.

[36] M. R. Hoffmann, J. A. Moss, M. M. Baum, Dalton Trans. 40 (2011) 5151-5158.

[37] H. He, C. Liu, K. D. Dubois, T. Jin, M. E. Louis, G. Li, Ind. Eng. Chem. Res. 51 (2012) 1184111849.

[38] S. Navalon, A. Dhakshinamoorthy, M. Alvaro, H. Garcia, ChemSusChem 6 (2013) 562-577.

[39] B. O'Regan, M. Grätzel, Nature 353 (1991) 737-740.

[40] M. Grätzel, Nature 414 (2001) 338-344.

[41] G. J. Meyer, Inorg. Chem. 44 (2005) 6852-6864.

[42] G. Li, C. Richter, R. L. Milot, L. Cai, C. A. Schmuttenmaer, R. H. Crabtree, G. W. Brudvig, V. S. Batista, Dalton Trans. (2009) 10078-10085.

[43] G. J. Meyer, ACS Nano 4 (2010) 4337-4343.

[44] J. H. Alstrum-Acevedo, M. K. Brennaman, T. J. Meyer, Inorg. Chem. 44 (2005) 6802-6827.

[45] W. J. Youngblood, S.-H. A. Lee, Y. Kobayashi, E. A. Hernandez-Pagan, P. G. Hoertz, T. A. Moore, A. L. Moore, D. Gust, T. E. Mallouk, J. Am. Chem. Soc. 131 (2009) 926-927.

[46] Z. Chen, J. J. Concepcion, J. W. Jurss, T. J. Meyer, J. Am. Chem. Soc. 131 (2009) 15580-15581.

[47] G. Li, E. M. Sproviero, W. R. McNamara, R. C. I. Snoeberger, R. H. Crabtree, G. W. Brudvig, V. S. Batista, J. Phys. Chem. B 114 (2010) 14214-14222.

[48] W. Song, Z. Chen, M. K. Brennaman, J. J. Concepcion, A. O. T. Patrocinio, N. Y. M. Iha, T. J. Meyer, Pure Appl. Chem. 83 (2011) 749-768.

[49] Y. Zhao, J. R. Swierk, J. D. Megiatto, Jr. et al., Proc. Natl. Acad. Sci. U. S. A. 109 (2012) 1561215616, S15612/1-S15612/8.

[50] T. W. Woolerton, S. Sheard, E. Reisner, E. Pierce, S. W. Ragsdale, F. A. Armstrong, J. Am. Chem. Soc. 132 (2010) 2132-2133.

[51] F. Lakadamyali, E. Reisner, Chem. Commun. 47 (2011) 1695-1697.

[52] T. Ogata, S. Yanagida, B. S. Brunschwig, E. Fujita, J. Am. Chem. Soc. 117 (1995) 6708-6716. 
[53] T. Ogata, Y. Yamamoto, Y. Wada, K. Murakoshi, M. Kusaba, N. Nakashima, A. Ishida, S. Takamuku, S. Yanagida, J. Phys. Chem. 99 (1995) 11916-11922.

[54] H. He, C. Liu, M. E. Louis, G. Li, J. Mol. Catal. A 395 (2014) 145-150.

[55] K. D. Dubois, A. Petushkov, E. G. Cardona, S. C. Larsen, G. Li, J. Phys. Chem. Lett. 3 (2012) 486-492.

[56] E. Finocchio, T. Montanari, C. Resini, G. Busca, J. Mol. Catal. A 204-205 (2003) 535-544.

[57] B. Kumar, M. Llorente, J. Froehlich, T. Dang, A. Sathrum, C. P. Kubiak, Annu. Rev. Phys. Chem. 63 (2012) 541-569.

[58] T. Petsi, G. D. Panagiotou, C. S. Garoufalis, C. Kordulis, P. Stathi, Y. Deligiannakis, A. Lycourghiotis, K. Bourikas, Chem. - Eur. J. 15 (2009) 13090-13104.

[59] M. Kohno, H. Ohya-Nishiguchi, K. Yamamoto, T. Sakurai, Bull. Chem. Soc. Jpn. 57 (1984) 932-937.

[60] B. M. Weckhuysen, A. A. Verberckmoes, M. G. Uytterhoeven, F. E. Mabbs, D. Collison, E. de Boer, R. A. Schoonheydt, J. Phys. Chem. B 104 (2000) 37-42.

[61] V. Kurshev, L. Kevan, D. J. Parillo, C. Pereira, G. T. Kokotailo, R. J. Gorte, J. Phys. Chem. 98 (1994) 10160-10166. 
Graphical Abstract

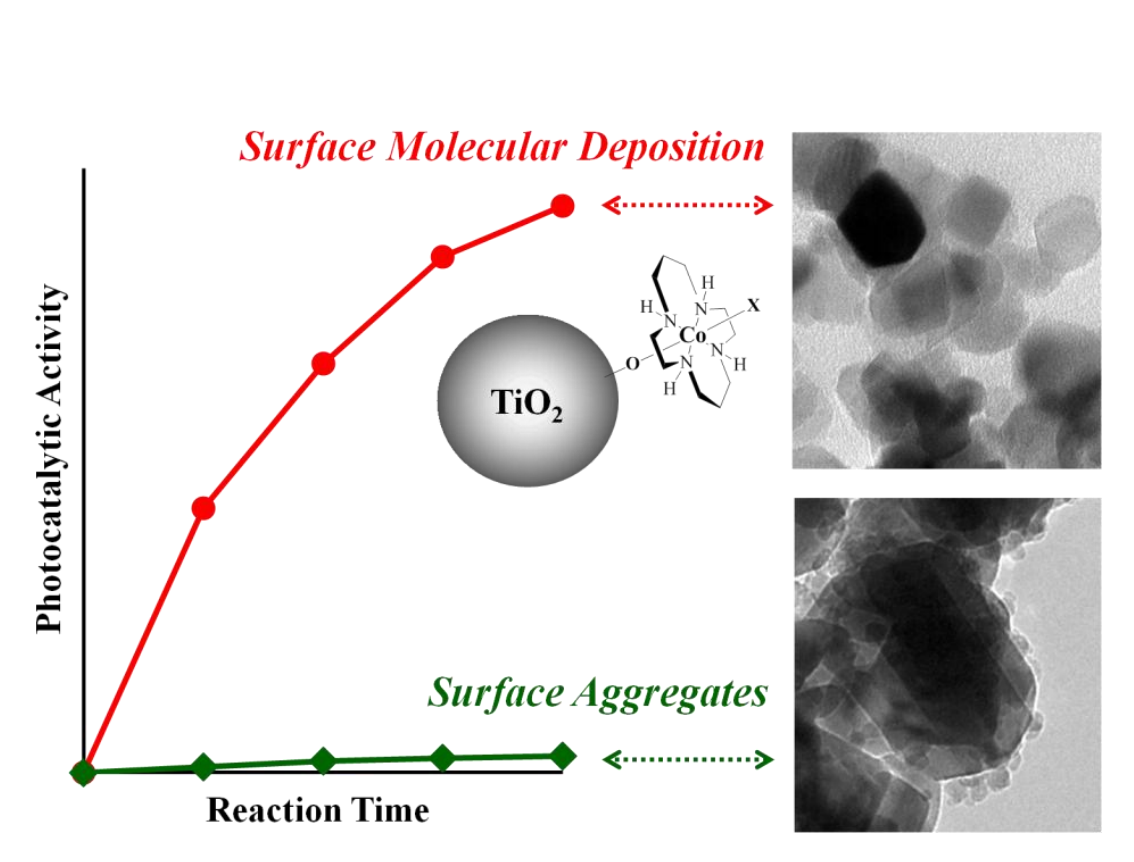
Graphical Abstract

.

